\title{
Design and Manufacture of a Large-Bore 10 T Superconducting Dipole for the CERN Cable Test Facility
}

\author{
D. Leroy, G. Spigo, A.P. Verweij \\ CERN, LHC Division, Geneva, Switzerland \\ H. Boschman, R. Dubbeldam, J, Gonzalez Pelayo \\ HMA Power Systems, Ridderkerk, The Netherlands
}

\begin{abstract}
A large-bore $10 \mathrm{~T}$ superconducting dipole magnet was designed and fabricated in close cooperation between CERN and HMA Power Systems. The dipole has a length of about $1.7 \mathrm{~m}$ and an aperture of $88 \mathrm{~mm}$ and is composed of two two-]ayer poles wound with NbTi cables cooled to $1.9 \mathrm{~K}$ to reach mapnetic inductions close to $10 \mathrm{~T}$. This dipole will be installed at the CFRN cable test facility and used as a background field magnet to test I.HC superconducting cables, In its large aperture up to four cable samples can be tested at the same time. 'Ihe mechanical design of the magnet is such that coil prestress variations between warm and cold conditions are kept within $20 \mathrm{MPa}$, A short model was also bujlt and cooled down in order to check and confirm with test results the mechanical behavior of the dipole. Magnetic measurements, at room temperature, were performed upon its arrival at CERN prior to installation in the test facility. The dipole was recently cooled down and tested. This paper will discuss the design, the main manufacturing steps and the initial test results.
\end{abstract}

\section{INTRODUCTION}

To fabricate the main dipole and quadrupole magnets for the LHC (Large Hadron Collider) accelerator at CERN, about $7000 \mathrm{~km}$ of superconducting (s.c.) cable are to be produced in the coming 5 years. A test lacility called FRESCA (Facility for REception of Superconducting CAbles) [1] was built at CERN to measure their electrical characteristics as woll as for general R\&D on s.c. cables. In this facility, conductors can be tested at temperatures between 1.8 and $4.4 \mathrm{~K}$ and currents up to $32 \mathrm{kA}$. To obtain a proper cable characterization, their critical current must be measured at fields around $8.4 \mathrm{~T}$ (operalional field of the $\mathrm{LHC}$ dipole). Morcover, the applied field must be uniform over a length of a few times the cable pitch $(-110 \mathrm{~mm})$. Nowadays, the unform background field volume is produced by a 56mn-single-aperture dipole $(9.5 \mathrm{~T}$ at $1.9 \mathrm{~K})$. Due to its small aperture, only 2 cables (width up to $16 \mathrm{~mm}$ ) per day can be tested. To test more (4 cables per day) and larger (width up to $25 \mathrm{~mm}$ ) conductors, the necessity of a large-bore-singleaperture dipole was established and its manufacturing launched in December 1997. For the sake of economy, an aperture of $88 \mathrm{~mm}$ was considered sufficient and agreed upon to use part of an existing tooling made for a previous dipole magnet [2]. This aperture is suitable to study various $R \& D$ topics on cables, such as current distribution among strands, Minimum Quench Energy, self-field effects and so on.

\section{DESCR]PTION OF THE MAGNET}

The main parameters of the magnet are listed in Table I whilc its cross-section and longitudinal cross-view are shown in Fig. I and Fig. 2 respectively. The two saddle-shape layers, forming the pole, are wound with two different trapezoidal conductors and joined together by an internal splice. The 16.7-mm-wide NbTi cables, used for winding the. inner and outer tayer, heve different shapes and thickness to
TARLE I

DIPOI.E: PARAMETERS

\begin{tabular}{|c|c|c|}
\hline 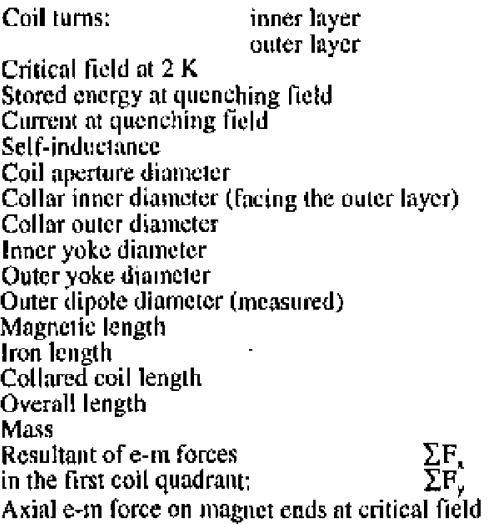 & $\begin{array}{l}48 \\
64 \\
10.15 \\
694 \\
1.3600 \\
7.5 \\
87.8 \\
1,59.20 \\
228 \\
228.8 \\
708 \\
-745 \\
1060 \\
1.360 \\
1.360 \\
=1700 \\
-4800 \\
3.74 \\
=2.77 \\
694\end{array}$ & $\begin{array}{l}\mathrm{T} \\
\mathrm{k} / \mathrm{m} / \mathrm{m} \\
\mathrm{A} \\
\mathrm{mH} / \mathrm{m} \\
\mathrm{mm} \\
\mathrm{mm} \\
\mathrm{mm} \\
\mathrm{mm} \\
\mathrm{mm} \\
\mathrm{mm} \\
\mathrm{mm} \\
m \mathrm{~m} \\
\mathrm{~mm} \\
\mathrm{~mm} \\
\mathrm{~kg} \\
\mathrm{MN} / \mathrm{m} \\
\mathrm{MN} / \mathrm{m} \\
\mathrm{kN}\end{array}$ \\
\hline
\end{tabular}

tailor the cutrent density to the maximum magnctic field seen by the layers and approximate best the cosine-theta current distribution of the pure dipole. The operating temperature is bolow the lambda point of superfluid helium ( $\mathrm{T}<2.16 \mathrm{~K}$ ) and close to $1.9 \mathrm{~K}$. Both cables are insulated with two $50-\mu \mathrm{m}$-thick, 11 -mm-wide polyimide tapes and one $55-\mu \mathrm{m}$ thick, 9 -mm-wide sticky polyimide tape capable to bond the adjacent conductors at $185^{\circ} \mathrm{C}$. The two 50 - $\mu \mathrm{m}$-thick tapes are placed one on top of the other and wrapped with edge-toedge pattern. To avoid any lack of insulation the uppermost lape covers the innermost by half a width. The $55-\mu \mathrm{m}$-thick tape is wrapped on the previous tapes with an opposite tilt and spaced by $2 \mathrm{~mm}$ to make channels for superfluid heliutn,

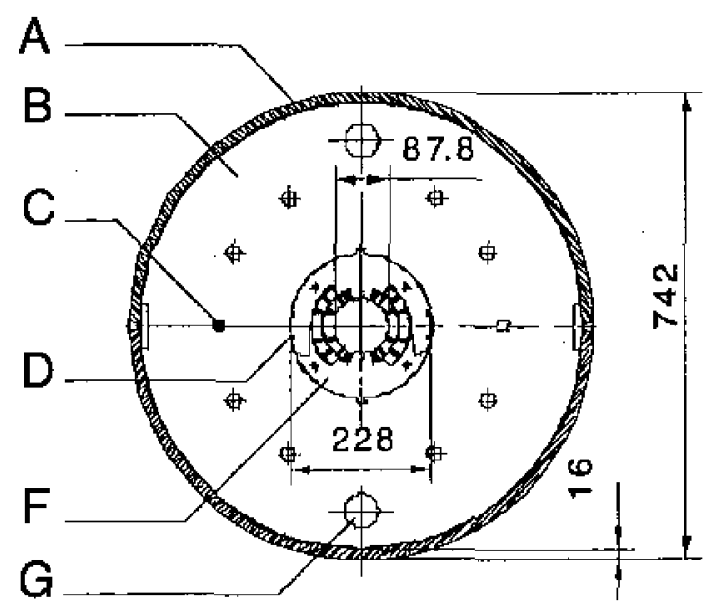

$\begin{array}{ll}\text { A) Shrinking Cylinder } & \text { B) Yoke } \\ \text { D) Collar Key } & \text { F) Collars }\end{array}$ C) Aligntuent Kcy Fig. 1. Cross section of the dipole magnet 


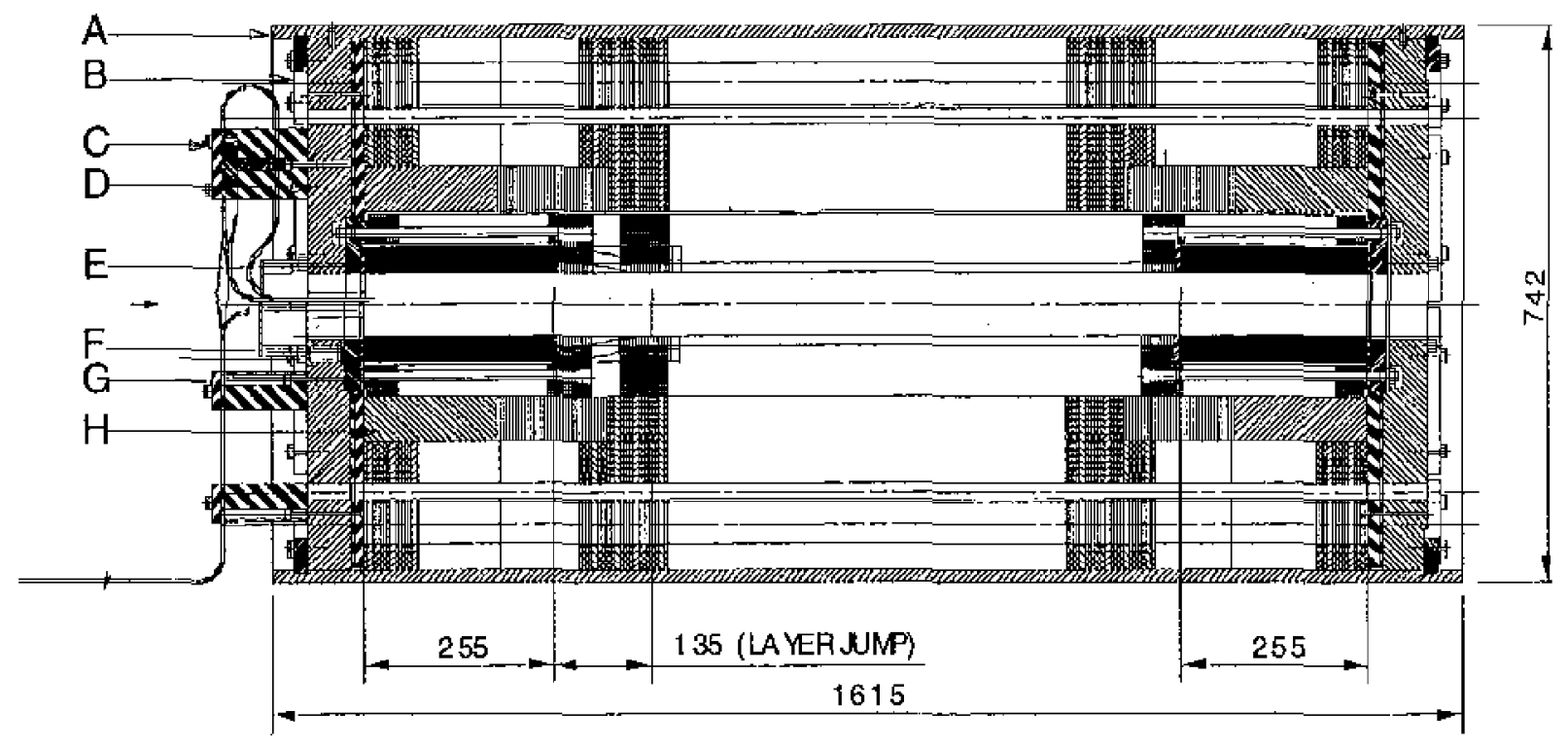

A) Shriaking Cylinder, B) 'Circlip', C) Insulation Blocks, D) End Plate, E) Upper Pole, F) Lower Pole, G) Collars and Cage, H) Non-magnetic Radial Insent

Fig. 2, Longitudinal section of the dijole

The two poles are clamped by austenitic steel (a.s.) circular collars joined together with a.s. square keys (collared coil), This assembly is sutrounded by a horizontally split iton yoke. The welding of the two $16-\mathrm{mm}-\mathrm{thick}$ a.s, sholls, placed on the external sutface of the yoke, drives the two half-yokes to come into contact under a pre-determined load so that a supplementary amount of stress is added to the alrcady compressed poles. The welding of the shrinking cylinder produces a total force grcater than $4.5 \mathrm{MN} / \mathrm{m}$ that is more than enough to insure a yoke completely closed in any situation. This value doubles at $1.9 \mathrm{~K}$ due to the difference in integrated thermal shrinkage of the materials used for the eylinder and the yoke. The collared coil is longitudinally loaded with 8 screws ( 4 on each side) located in 60 -mm-thick a.s. end plates. Each screw applies an axial pre-load of $20 \mathrm{kN}$. The longitudinal magnetic force is transicrred from the end plates to the shrinking cylinder by means of "circlip"like devices. These are bolted to the plate and positioned in the 5-mm-deep circumferential groove made in the inner surface of the cylinder (see Fig. 2).

\section{III.THE SuperConduCTING CABLE}

The strand material is $\mathrm{Nb} 47 \mathrm{Ti} / \mathrm{Cu}$ composite with filanients of $5 \mu \mathrm{m}$ of diameter. Both types of strands have a

TABLE II

CHAARCTERTSTIS DATA OF THE CABI F

\begin{tabular}{|c|c|c|}
\hline & INNER LAYER & OUTER LAYEK \\
\hline $\begin{array}{l}\text { Diameter of strand (mm) } \\
\text { Cu/Sc ratio } \\
\text { Filament size ( } \mu \text { m) }\end{array}$ & $\begin{array}{l}1.1 \\
1.6 \\
5\end{array}$ & $\begin{array}{l}0.87 \\
5.87 \\
5\end{array}$ \\
\hline $\mathrm{J}_{\mathrm{c}}$ at $7 \mathrm{~T}$ and $4.2 \mathrm{~K}(\mathrm{~A})$ & 16226 & 12715 \\
\hline $\begin{array}{l}\mathrm{l}_{\mathrm{c}} \text { at } 10 \mathrm{~T} \text { and } 1.9 \mathrm{~K}(\mathrm{~A}) \\
\text { Number of strands } \\
\text { Mid thickness bare (mm) } \\
\text { Widtlu bare (mom) } \\
\text { Keystone angle (degrees) } \\
\text { Number of filanterts }\end{array}$ & $\begin{array}{l}16484 \\
30 \\
1.965 \\
16.7 \\
1.20 \\
20328\end{array}$ & $\begin{array}{l}12624 \\
38 \\
1.560 \\
16.7 \\
0.83 \\
9438\end{array}$ \\
\hline $\begin{array}{l}\mathrm{dl} / \mathrm{dB}(N / \mathrm{T}) \text { at } 1.9 \mathrm{~K} \\
\text { n value }\end{array}$ & $\begin{array}{l}-5200 \\
23\end{array}$ & $\begin{array}{l}-4477 \\
25\end{array}$ \\
\hline
\end{tabular}

$1-\mu \mathrm{m}$ thick Sn5Ag coating. To avoid slatp edges on the thin side of the cables while keeping the current density inside the conductor, the compaction ratio of the cable is limied to $91 \%$. Critical current measurentents made on strands, extracted after cabling, indicate a current degradation lower than $3 \%$. The average value of the interstrand resistance $R c$, measured in a previous magnet [4], is $16 \mu \Omega$, large enough to limit the dynamic effects during ramping. The main cable paramelers are listed in Table II.

\section{The Magnetic Design of tie Dipole}

The position of the coil turns is optimized with the computer program ROXIE [3|. The inter layer is composed of 24 turns, divided into four blocks by three copper wedges. Starting from the layer midplane, the number of turns per block is $9,9,4$ and 2 . The outer layer is composed of 32 turns, divided into three blocks. Starting from the layer midplane, the number of turns per block is 12,11 and 9 . The Jocation of the conductors is such that the variation of peak ficld among cables belonging to the three uppermost blocks of the inner layer is very limited and within $2-3 \%$. The iron contribution to the total dipole magnetic induction, at low fied, is $23 \%$ while at high field it is close to $17 \%$. The width of the yoke $(239.5 \mathrm{~mm})$ satisfies the requirements of a low fringe ficld (51 $\mathrm{mT}$ at full excitation) and a weight of the dipole lower than $50 \mathrm{kN}$ (test facility supports). T'/ye bighest field of saddle-shaped windings is positioned in the portion of the coll end close to the straight part (coil transition region). This implies a reduction of the eurrent (lield) margin for the windings localed in that area. To avoid this, the ficld in the end region of the dipole was lowered, with respect to the straight part, by 1 ) spreading out the windings in the coil ends by means of large epoxy-fiberglass spacers that roughly reproduce the arrangement of the coil blocks (only the two imer layer uppermost conductors were spaced separately), and 2) placing a 70 -mm-wide, non-magnetic radial insert between the collared coil and the yoke so as to reduce the jron contribution by more than half. 


\section{THE MECHANICAL DESIGN OF THE DIPOLE}

\section{A. Cross Section Basic Principles and Features}

The mechanical design is based on the extended line-to-line fit concept. This means that, in any situation, the outer radius of the collared coil is the same as the yoke inner one (no loss of contact can take place between yoke and collars) and that the collar-yoke circular contact is spread over a $2 \pi$ angle. This sots a quasi-infinite tigid boundary for the poles that, together with low friction interfaces among the dipole parts (coils, collars, yoke and shrinking cylinder), establishes an excellent transmission of the horizontal component of the magnetic force. This gives namely: 1) a dramatic reduction of collared coil deformation due to bending, 2) a stable field quality at any magnetic field, 3) a full mechanical support of poles, and 4) an unloading of the upper portion of the coil, during excitation, merely due to the azimuthal component of the magnetic force (mininum stress component coming from bending). This mechanical configuration well supports and confines any coil transition region (ramp splice area and coil ends) where the pole stress has the tendency of being less predictable. As the outer contour of the collared coil al ways fits the yoke inner one, the collar spring constants along the azimuth do not change, even if pole stresses vary because of the different thermal shrinkages of dipole parts. Moreover, the pole unloading behavior, essentially given by the compressive components of the magnetic force (negligible bending), permits the lowering of the stress needed to hold the layers in contact with the collar pole at full excitation. The inctease of rigidity of the collared coil, modeled as a thin ring, versus the area of the applied load is shown in Table III. The collar was carefully optimized to fulfil the following requirements: 1) protection of the layers from overloads occurring during the various assembly phases, 2) correct compression of the poles, and 3) possibility to accept collaring-press misalignments up to $150 \mu \mathrm{m}$ both in longitudinal and horizontal direction (over $200 \mathrm{~mm}$ ). This was obtained by properly shaping and locating the collar keyways. To fulfil the first requirement, the flat bottom surface of the collar was used as a stopper to protect the poles from an excessive overloading during collaring. To satisfy the third need, the height of the collar keyway was increased by $100-120 \mu \mathrm{m}$ with respect to the dimension of the key. To overcome the greater collaring spring back (loss of coil prestress), the upper and lower collar keyways were placed at distances from collared coil midplane different by $150 \mu \mathrm{m}$. During the wolding of the shrinking cylinder, the gap between collar keyways and keys (keyway space) disappears making the keys act as a stopper limiting the increase of coil stress to a well defined value. The thiçkness of the shrinking cylinder was correlated to the quantity set by combining the keyway space and the vertical collared coil deformation (combined deformation value). The combined deformation value of $390 \mu \mathrm{m}$ (100- $\mu \mathrm{m}$ keyway space plus a collared coil vertical deformation of $290 \mu \mathrm{m}$ produced by an azimuthal stress in layers of $65 \mathrm{MPa}$ ) was found the right value. This quantity conciliates the following opposite needs, namely: 1) limitation of pole overloading during collaring, 2) sufficient coil prestress after collaring, 3) easy assembly of the collared coil in the yoke due to its non-excessive vertical deformation after collaring and, 4) provision of a sufficient iron mating force to keep the yoke closed at full excitation.
TABLE III

COL.LARED COHE RIGIDTIES AND BENDING MOMENTS (RATTO BETWEEN THE ACTUAL VALUE AND THE VALUE AT ZERO DEGREE)

\begin{tabular}{|c|c|c|c|c|}
\hline ANCILE & \multicolumn{2}{|c|}{ INCREASE OF RIGIDITY } & \multicolumn{2}{|c|}{ BENDING MONENT } \\
\hline $\begin{aligned} & 0 \\
\pm & 30 \\
\pm & 60 \\
\pm & 90\end{aligned}$ & \multicolumn{2}{|c|}{$\begin{array}{c}1 \\
2.4 \\
4.3 \\
13.5 \\
\end{array}$} & & $\begin{array}{c}1 \\
0,629 \\
0.303 \\
0\end{array}$ \\
\hline \multicolumn{5}{|c|}{$\begin{array}{l}\text { TABLE IV } \\
\text { AYERAGE COMPUTT:D LAYYR AZIMUTHAL STRESS HISTORY (MPa) }\end{array}$} \\
\hline & COLLARING & YOKING & $2 \mathrm{~K}$ & FULL FIELD \\
\hline $\begin{array}{l}\text { INNER } \\
\text { OUTER }\end{array}$ & 65 & $\begin{array}{l}90.3 \\
85.9\end{array}$ & $\begin{array}{l}70.3 \\
68.8\end{array}$ & $\begin{array}{r}-5-10 \\
-15-20\end{array}$ \\
\hline
\end{tabular}

Computations showed that a thickness of about $14 \mathrm{~mm}$ was enough to meet the requirements. For the sake of time and prompt availability, a 16-mm-thick as. cylinder was used. The calculated average values of coil azimuthal stress are shown in Table IV.

\section{B. Longitudinal Section}

Training quenches are usually detected in the magnet ends and in areas close to them. A high magnetic field gradient and a sharp difference of azimuthal stress in the transition regions (zones betwcen the end and the straight part) are the main causes. To partly surmount this undesired response, the following sixfold approach was considered: 1) winding procedure providing the minimum stored bending energy (i.e. low shear stress), 2) good compaction of conductors in the ends (i.c. negligible changes between uncured and cured end geometry), 3) reduced longitudinal field gradient $(\partial \mathrm{B} / \partial z)$ by spacing the conductors in the ends, 4) azimuthal low prestress (from 10 to $25 \mathrm{MPa}$ ) in the ends permitted by the good cohesion of cables (see point 2), 5) smooth stress gradient $\left(\partial \sigma_{0} / \partial \mathrm{z}\right.$ ) in the coil transition region (reduced shear stress) realized by properly shimming the pole midplane over $150 \mathrm{~mm}(450 \mathrm{kPa} / \mathrm{mm})$, and 6) mechanical compaction of the coil extremities achieved by longitudinally loading the collared coil ends with the 'end cage' [4], [5]. The external view of the 'cage' (bolts and 'backing plate' against which the coil ends react) is shown in the Fig. 3.

\section{TEST OF THE MOCK-UP}

To characterize better the mechanical behavior of the straight part, a 200-mm-long model, shown in Fig. 4, was made. This model was instrumented with 4 capacitive gauges (during the tests one broke down) calibrated at both room and $\mathrm{LN}_{2}$ lemperature. To obtain all information necessary to adjust the pole stress in the full-scale dipole, the model was collared, welded, cooled down and warmed up. It turned out

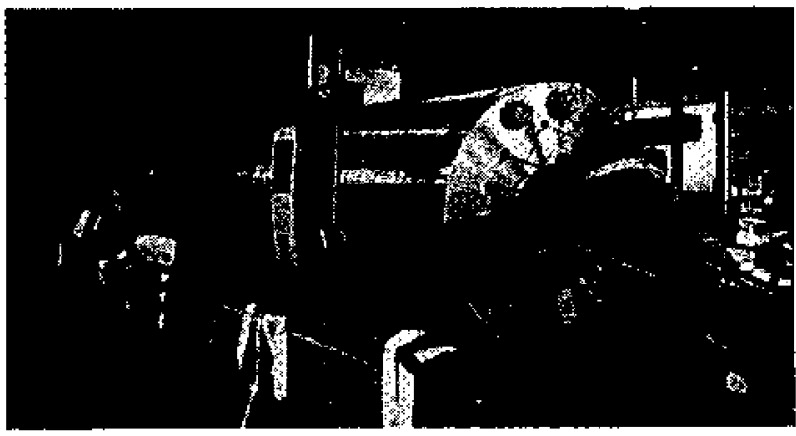

Fig. 3. Collared coil (particular of the "End cage') 


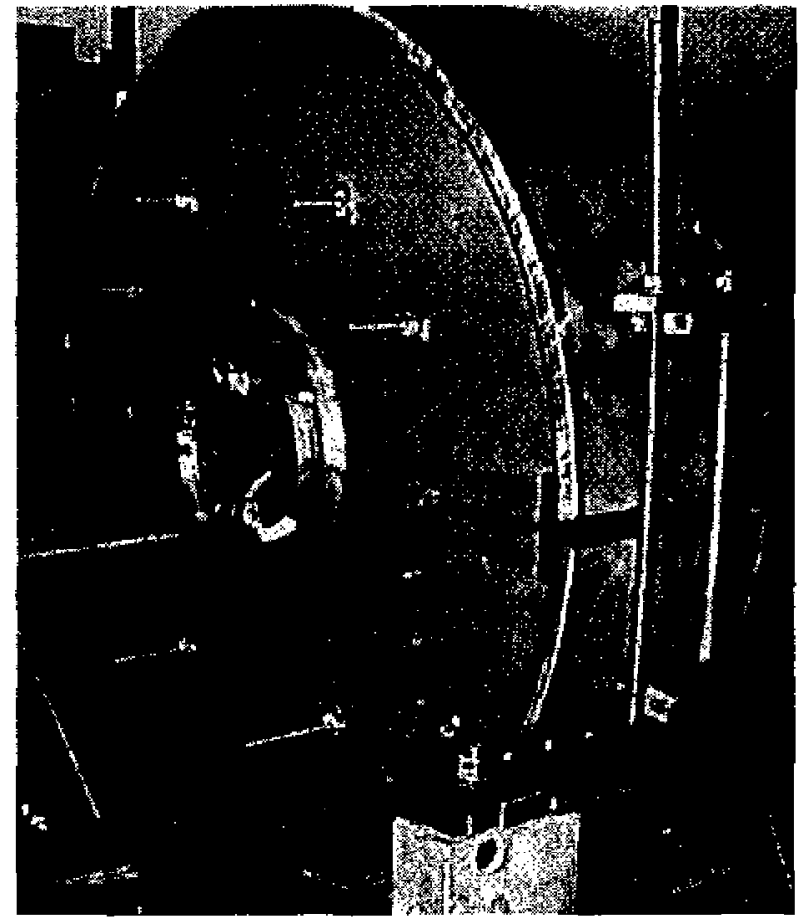

Fjg. 4. 200-mm-long Mock-up

that the mechanical radial tolerances between collared coil and yoke added up $10200-\mu \mathrm{m}$-global interference (larger than the design value of about $100 \mu \mathrm{m}$ ). To test and check how the mechanical structure worked, it was decided not to adjust this value. In fact, a closed gap would have limited the understanding of the mechanics during the different steps (assembly, cooldown, warm-up, etc.). Before welding, the average yoke gap was around $800-900 \mu \mathrm{m}$, as expected by piling up all parts together without any stress. After welding, the yoke gap shrunk by $300-400 \mu \mathrm{m}$ to an average value of about $450-500 \mu \mathrm{m}$. The assembly was cooled down to $77 \mathrm{~K}$. The loss of pole stress, generated by the different integrated shrinkages of layers $\left(\sim 6 \times 10^{3}\right)$, collars $\left(\sim 2.7 \times 10^{-3}\right)$, yoke $\left(\sim 2 \times 10^{-3}\right)$ and shrinking cylinder $\left(\sim 3 \times 10^{-3}\right)$, was largely compensated by the growth of coil elastic modult (more than $50 \%$ measured on samples of similar conductors), together with a gap closure during cooldown. The measurements of stresses taken during the fabrication and cool down are shown in Table V. After completion of the cool down, the magnet was taken out of the $\mathrm{LN}_{2}$ bath and the yoke gap measured. It turned out that the yoke was completely closed. In cold condition, the value of the shrinking cylinder stress is estimated to vary between 170 and $210 \mathrm{MPa}$. After warming up, the yoke gap was measured again and resulted smaller than the one measured after welding. As expected, the yoke gap had a tilted geometry with minimum opening at the yoke-cylinder interface $(160 \mu \mathrm{m})$ and maximum one $(250 \mu \mathrm{m})$ close to the collared coil. Values and shape of the gap show that all pieces came into intimate contact and their surfaces match each other adcquatcly. This means that the structure well adjusts itsclf coping with appreciable dimensional variations (piling-up tolerance of $110 \mu \mathrm{m}$ between collared coil and yoke) without changing its mechanical behavior or modifying the round contous.
TAHLE $V$

MOCK-UP L.AYER AZIMUTHAL STRESS (MPR)

\begin{tabular}{cccc}
\hline STEP & S.P.I.R. & S.P.L.L & S.P.O.L. \\
\hline COLLARING PEAK STKESS & 135 & 130 & 131 \\
COLLARING & 96 & 97 & 87 \\
WEI.DING & 113 & 117 & 111 \\
COOL DOWN & 118 & 125 & 103 \\
YOKE TAKEN OFF & 94 & 89 & 81 \\
\hline
\end{tabular}

S.P.J.L.R. =Straight Pant Inner Left/kight S.P.O.L./R. =\$traight Patt Ouler Lefr/Right

VII. FABRICATION OF THE MAGNE'T

\section{A. Curing Cycle}

As the thickness of cable insulating tapes was at its maximum tolerance, the generally utilized baking-cycle sizing phase (curing mold completely closed at pressures between 90 and $100 \mathrm{MPa}$ and temperalures close $10135^{\circ} \mathrm{C}$ ) was infeasible and a different approach had to be adopted. The sizing plase was based on a pre-determined pressure plateau (80-90 MPa) and on a raising temperature, imperatively below the bonding one, at which the mold closed down. The combined effects of pressure and temperature enabled the insulation thickness to shrink permitting the closure of the mold at 145-150 (inner layer) and $165-170{ }^{\circ} \mathrm{C}$ (outer layer). The pressure plateau was applied at $100-110^{\circ} \mathrm{C}$ to avoid the bonding, at an incorrect geometry, of the cables in cottact with the surfaces of the end spacers covered with a thin layer of epoxy resin (curing temperature of $130^{\circ} \mathrm{C}$ ).

\section{B. Collaring}

During collaring, to limit any deformation coming from bending, leading to undesired shoar stresses, the cylindrical shape of the pole must be maintained. To do so, the collared coil was pressed with a circular tooling surrounding the collars completely (only the volume set up for the insertion of the keys was free). The collaring was done without using any coil radial support (collaring mandrel). After collaring, the bolts of the end cage were tightened under a torque close to $50 \mathrm{Nm}$. No lubrication was deposited on the threads to avoid any pollution. The estimated global force acting on the coil ends ranges between 35 and $46 \mathrm{kN}$.

\section{Welding}

The welding process consists of 2 TIG (Tungsten Inert Gas) root passes completed with 4 MIG (Metal Inert Gas) weld beads. The pole stress was monitored and increased all along the welding phase reaching values close to the calculated ones. After the third MIG pass, this was almost negligible indicating that the yoke gap closed down and that the structure was correctly assembled. To measure the stress, the dipole was equipped with two instrumented collar packs (the first located in the straight part and the second in the ramp splice). Each pack had 4 capacitive gauges placed between the collar pole and the layers. Table VI and VII present the measurements of the azimuthal stress taken during manufacturing. The data show that, after removing the collaring load, the average porcentage of left-and-right difference in the stress of the layers is kept within $5 \%$ in the straight part while it is slightly larger (10\%) in the rampsplice region where the pole geometry in quite asymmetrical. This behavior was also confirmed by the subsequent welding operations where the percentage of lott-and-right stress variation was even improved. This signifjes that the mechanical structure is well balanced and properly centers itself providing a symmetrical distribution of the load. 
TABEE VI

COL AZIMUTHAL STRESS DURINO COLLARING (MPa)

\begin{tabular}{cccccccccc}
\hline & \multicolumn{2}{c}{ S.P.I. } & \multicolumn{2}{c}{ S.P.O. } & \multicolumn{2}{c}{ R.S.I. } & \multicolumn{2}{c}{ R.S.O. } \\
\hline STEP & L & R & L & R & L & R & L & R \\
\hline 1 & 0 & 0 & 0 & 0 & 0 & 0 & 0 & 0 \\
2 & 114 & 117 & 120 & 134 & 110 & 115 & 124 & $13]$ \\
3 & 66 & 69 & 59 & 67 & 68 & 75 & 71 & 78 \\
4 & 66 & 69 & 59 & 67 & 69 & 75 & 71 & 78 \\
5 & 63 & 63 & 57 & 60 & 67 & 73 & 65 & 74 \\
\hline
\end{tabular}

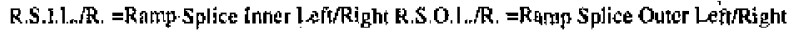
1) Start up, 2) Kuy inserion, 3) Loau removed, 4) Out of Ilye paess, 5) Afrer one month

TABLE VII

COIL AZLMUTIAL. STRESS DURING WILDING (MPa)

\begin{tabular}{|c|c|c|c|c|c|c|c|c|}
\hline & \multicolumn{2}{|c|}{ S.P.I. } & \multicolumn{2}{|c|}{ S.P.O. } & \multicolumn{2}{|c|}{ R.S.I. } & \multicolumn{2}{|c|}{ R.S.O. } \\
\hline PASS & $\mathrm{L}$ & $\mathbf{R}$ & $\mathrm{L}$ & $\mathrm{R}$ & L & $\overline{\mathrm{R}}$ & L & $\bar{R}$ \\
\hline 0 & 63 & 63 & 57 & 61 & 68 & 73 & 65 & 74 \\
\hline $\mathrm{I}(\mathrm{T} \mid \mathrm{G})$ & 66 & 65 & 59 & 62 & 69 & 75 & 67 & 76 \\
\hline $2(\mathrm{~T} \mid \mathrm{G})$ & 67 & 66 & 62 & 64 & 70 & 77 & 69 & 77 \\
\hline I (MIG) & 75 & 74 & 74 & 72 & 76 & 82 & 74 & 84 \\
\hline $2(\mathrm{MLIG})$ & 79 & 80 & 79 & 80 & 81 & 88 & 81 & 92 \\
\hline 3 (MIJ) & 78 & 80 & 79 & 80 & 81 & 88 & 81 & 93 \\
\hline 4 (MIG) & 83 & 8.5 & 85 & 84 & 86 & 92 & 87 & 98 \\
\hline CERN & 83 & 80 & 81 & 81 & 87 & 93 & 85 & 95 \\
\hline
\end{tabular}

\section{Magnetic MEAsUREMENTS}

The quality of field, along the longitudinal axis, is measured using rotating harmonic coils. Multipole components shown in Table VIII are measured, at room temperature, in the magnet straight part (injecting current of i5 A). To better gauge the dipole field quality quality, the results are compared with the computed values. At low field, the measured transfer function of current versus magnetje induction is $784.80 \mu \mathrm{T} / \mathrm{A}$, very close to the calculated one (784.44 $\mu \mathrm{T} / \mathrm{A})$. The normal sextupole component is larger than the calculated one, as expected from the' coil size measurements (inner layer smaller by $60-80 \mu \mathrm{m}$ at $85 \mathrm{MPa}$ ). The reason of the large value of skew quadrupole is not understood yet. A possible source might be an open gap but, as said betore, the yoke gap is fully closed, and up-and-down shifts of the coil-midplane ranging from 100 to $150 \mu \mathrm{m}$ seem rather improbable or to be excluded looking at the data collected during manufacturing (traveler). In any case, this large skew component does not have any practical conscquence for the electrical measurements of the cables.

\section{TRaining BEHAVIOR}

Upon its artival at CERN, the magnet was installed in its definite vertical cryostat, in which the temperature of the superfluid-helium bath can be regulated between 1.7 and $2.1 \mathrm{~K}$. The dipole was cooled and tested. The magnet quench history is presented in Fig. 5 . The ficld of $9.5 \mathrm{~T}$, lixed for the

TABLE VIII

COMPUTED AND MEASURED NORMAL AND SKEW MULTIPOLE COMPONENTS (IN UAITS OF $10^{-1}$ RIILA'TIVE FIELD ERROR AT $17 \mathrm{~mm}$ )

\begin{tabular}{ccccc}
\hline $\mathrm{n}$ & Computed $\mathrm{b}_{\mathrm{n}}$ & Computed $\mathrm{a}_{\mathrm{n}}$ & Mensured $\mathrm{b}_{\|}$ & Measured $\mathrm{a}_{\mathrm{u}}$ \\
\hline 2 & 0 & 0 & -0.219 & 2,366 \\
3 & 0.568 & 0 & 1.400 & 0.104 \\
4 & 0 & 0 & -0.084 & 0.508 \\
5 & -4.695 & 0 & -3.886 & 0.003 \\
6 & 0 & 0 & -0.021 & -0.186 \\
7 & 0.892 & 0 & 0.944 & -0.061 \\
8 & 0 & 0 & -0.017 & -0.057 \\
9 & 0.001 & 0 & -0.010 & -0.012 \\
10 & 0 & 0 & -0.026 & -0.015 \\
11 & 0 & 0 & -0.024 & 0.002 \\
\hline
\end{tabular}

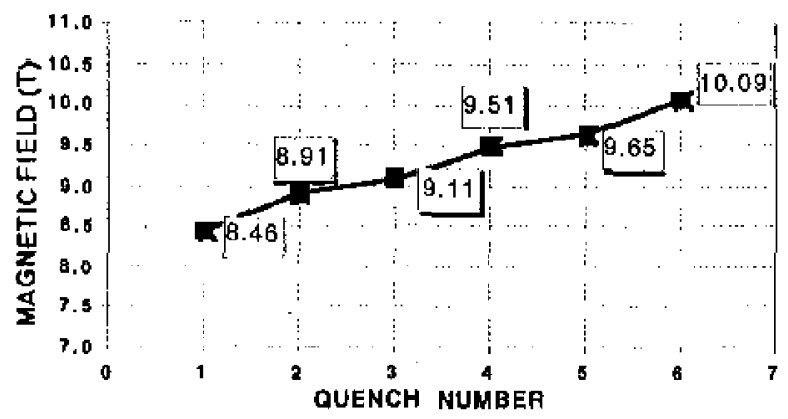

Fig.5. Quench History

testing of s.c. cables, was exceeded at the fifth quench and a central ficld of $10.09 \mathrm{~T}$ was attained after the sixth quench.

\section{CONCLUSIONS}

To meastre the ejectrical characteristies of LHC cables and do R\&D on s.c. cables, a large bore $10 \mathrm{~T}$ background dipole was built and installed at CERN. This dipole was designed and manufactured following the concept of the extended line-to-line fit whose validity was successfully confirmed during fabrication and in the test campaign. Even though the average azimuthal stress of the coil, after collating, was around $65 \mathrm{MPa}$, the very high rigidity of the dipole mechanical structure is such that lower stress valucs (around $45-50 \mathrm{MPa}$ ) are permilted. The data indicate that coil compressive stresses can be increased by almost any given quantity during welding by properly shaping the contour of the collar (keyway region). The correct slaping of the collars also results in a low impact of press tolcrances (within a given range) on the response of the collared coil structure during collaring so that a no-risk collaring can be per[ormed even in presses with rather ample misalignments. Furthermore, the auto-centering of the collared coil structure leads to a symmetrical distribution of the load that mininizes the left-and-right stress variation, indicating that the structure is insensitive to the adopted welding method. The test results prove that this technology is mature and reliable and that industry is able to fabricate magnets reaching the critical ticld in few quenches without any major problem.

\section{ACKNOWLEDGMENT}

The authors wish to thank J. van Leenen for his precious contribution during the manufacturing of the magnet, $D$. Giloteaux and $O$. Pagano for the magnetic measurements at room temperature. Special thanks to J. Genest and J. P. Marzolf for the insiallation of the dipole and to $\mathrm{N}$. Simonne for his large support in setting up the test station and during the cold tests. Warm thanks to M. Parent and $Y$. Vanenkov for coil instrumentation and stress measurements.

\section{REFERENCES}

[1] A Verweij et al., "1.9 K Test facility for the Reception of the Superconducling Cables for the LHC", ASC "98, Palm Spring, $\mathrm{CA}$, USA, September 1998.

(2) L, Bottura et al, "Testing of a Large Bore Single Aperture 1-Metre Superconducting Dipoles Made with Phenolic lnsents", EPAC 98 Prosecedings, CD locotion 2008

[3] S. Russerschuck, Scftware Paikage ROXIE 4.2.

[4] 1. Ahlbilck ot al., "Construction of a $56 \mathrm{~mm}$ Aperture High-Field TwinAperture Superconducting Dipole Model Magnet", IEEE Trans, on Magnetics, July 1996, vol 32, No. IV, pp. 2097-2100.

[5] D. Leroy et al., "Design Features and Performance of a $10 \mathrm{~T}$ Twin Aperture Model Dipole for LHC", MT'-15 Proceedings, 1998, Part One, pp. 119-122, 